\title{
Oncogene FPS-FES
}

National Cancer Institute

\section{Source}

National Cancer Institute. Oncogene FPS-FES. NCI Thesaurus. Code C18453.

Human Oncogene FPS-FES is a mutated variant of FES Gene (FES/FPS Subfamily), which encodes 822 aa 93-kDa Tyrosine-Protein Kinase FES/FPS, a tyrosine-specific protein kinase involved in normal hematopoiesis and containing an $\mathrm{FCH}$ and $\mathrm{SH} 2$ domain. The FES chromosomal location is linked to a translocation identified in patients with acute promyelocytic leukemia. A truncated transcript is generated utilizing a start site in a far downstream exon. Oncogene FPS-FES disrupts normal cell function. 